\title{
Factors associated with immunisation coverage and timeliness in New Zealand
}

Cameron C Grant, Nikki M Turner, Deon G York, Felicity Goodyear-Smith and Helen A Petousis-Harris

\begin{abstract}
\section{Background}

Immunisation coverage in New Zealand is lower than what is necessary to prevent large epidemics of pertussis. Primary care is where most immunisation delivery occurs. General practices vary in their structure and organisation, both in a general sense and specifically with respect to immunisation delivery.

Aim

To identify the structural and organisational characteristics of general practices associated with higher immunisation coverage and more timely immunisation delivery.

\section{Design of study}

A random sample of practices during 2005 and 2006.

\section{Setting}

General practices in the Auckland and Midland regions, with over-sampling of indigenous Maori governance practices.

\section{Method}

Practice immunisation coverage and timeliness were measured. Primary care practice characteristics relevant to immunisation delivery by the practice were described. Associations of these practice characteristics with higher practice immunisation coverage and more timely immunisation delivery were determined.

\section{Results}

A total of $124(61 \%)$ of 205 eligible practices were recruited. A median (25th to 75 th centile) of $71 \%$ $(57-77 \%)$ of registered children at each practice were fully immunised, and 56\% (40-64\%) had no immunisation delay. In multivariate analyses, both practice immunisation coverage $(P<0.001)$ and timeliness $(P<0.001)$ decreased with increased social deprivation. After adjustment for socioeconomic deprivation, region, and governance, immunisation coverage and timeliness were better at practices that enrolled children at a younger age (coverage: $P=0.002$; timeliness $P=0.007$ ), used one of the four available practice management systems (coverage: $P<0.001$; timeliness: $P=0.006$ ), and had no staff shortages (coverage: $P=0.027$; timeliness: $P=0.021$ ).

\section{Conclusion}

Practice immunisation coverage and timeliness vary widely in New Zealand. General organisational and structural aspects of general practices are key determinants of general practice immunisation delivery.

\section{Keywords}

delivery of health care; family practice; immunisation; primary health care.

\section{INTRODUCTION}

Immunisation is the most cost-effective intervention modern medicine has to offer. ${ }^{1}$ To achieve the full benefits of immunisation, both high coverage and timely delivery of scheduled immunisations are necessary.

Immunisation coverage in New Zealand (NZ) is mediocre. In the 2005 national survey, only $77 \%$ of children at 2 years of age had received all scheduled childhood immunisations. Coverage for indigenous (Maori) and Pacific children is lower, despite the NZ Ministry of Health's goal of $95 \%$ for all. ${ }^{2}$ As a consequence, NZ continues to experience large epidemics of pertussis. The infant pertussis hospitalisation rate is three to six times higher than contemporary rates for Australia, England, and the $\mathrm{US}^{3-6}$

Timeliness of delivery is as important as coverage. Delay in receipt of the first vaccine dose in the primary series is one of the strongest predictors of subsequent incomplete immunisation. ${ }^{7}$ Delay in

CC Grant, PhD, FRACP, associate professor in paediatrics, Department of Paediatrics, Faculty of Medical and Health Sciences; NM Turner, MPH, FRNZCGP, honorary senior lecturer; DG York; BA(Hons), MA, research assistant; HA Petousis-Harris, BSc, honorary senior lecturer, Immunisation Advisory Centre; F Goodyear-Smith, FRNZCGP, MGP, professor in general practice, Department of General Practice and Primary Health Care, School of Population Health, University of Auckland.

\section{Address for correspondence}

Cameron Grant, Department of Paediatrics, Faculty of Medicine and Health Sciences, The University of Auckland, Private Bag 92019, Auckland, New Zealand.

E-mail: cc.grant@auckland.ac.nz

Submitted: 16 April 2009; Editor's response: 2 June 2009; final acceptance: 25 August 2009.

(c)British Journal of General Practice

This is the full-length article of an abridged version published in print. Cite this article as: Br J Gen Pract 2010; DOI: 10.3399/bigp10X483535. 
receipt of any of the three infant doses of pertussis vaccine increases the risk of hospital admission with pertussis. $^{8}$

Socioeconomic factors, healthcare system factors, and parental attitudes contribute to incomplete immunisation. ${ }^{9}$ Research to date in NZ on immunisation coverage has focused on the characteristics of the child, family, or household. Internationally, it is well recognised that health systems and their providers make significant contributions to gaining and maintaining high coverage. ${ }^{10,11}$ The identification of health system barriers has been an essential component of immunisation coverage improvements in Australia and the US. ${ }^{12,13}$

Most immunisation delivery occurs in primary care. While the attitude of healthcare providers is crucial to achieving maximal immunisation uptake, healthcare structural and organisation factors also determine immunisation delivery. ${ }^{14}$ Aspects that have been identified as important include record keeping and documentation, recall/reminder, and tracking systems and practice settings. ${ }^{15-17}$

The aim of this study was to determine the structural and organisation characteristics of general practices that are associated with higher immunisation coverage and more timely immunisation delivery.

\section{METHOD}

\section{Study design and setting}

Approval was obtained from the Ministry of Health Ethics Committee. General practices in two NZ regions (Auckland and Midland) were enrolled during 2005 and 2006. Approximately $50 \%$ of all NZ children aged 0 to 4 years reside in the study region.

A random sample of practices was recruited, with stratification by region and oversampling of Maori governance practices (these are independent Maori health providers that target services primarily towards Maori and have a Maori management and governance structure).$^{18}$ There were 11 such Maori governance practices in Auckland and 50 in Midland.

A total of 213 of the 517 practices in the study region were selected. In Auckland this included all Maori governance practices plus a random $29 \%$ of the non-Maori governance practices. In Midland it included a random sample of $62 \%$ of the Maori governance practices and $61 \%$ of non-Maori governance practices. From this sample it was possible to recruit 124 practices: 72 from Auckland and 52 from Midland.

\section{Sample size estimates}

A total of 124 practices was sufficient to yield $80 \%$

\section{How this fits in}

General practices are where most immunisation delivery occurs. Preventive

health service delivery by practices requires appropriate structure and

organisation. General organisational characteristics of practices (age when

children registered, type of practice management system used, and stability of

staffing) are key practice determinants of immunisation delivery. These areas,

rather than more immunisation-specific factors, should be addressed first when

seeking to improve general practice immunisation delivery.

power to show statistical significance at the $5 \%$ level for a practice characteristic associated with higher coverage or more timely immunisation delivery. These calculations assumed the characteristic being examined had a frequency between $10 \%$ and $70 \%$ and was present in $20-25 \%$ more of the practices with higher coverage or better timeliness.

\section{Data collection and measurements}

Practice immunisation coverage and timeliness were measured by electronic audit of the immunisation records for all children aged 6 weeks to 23 months. During this study the NZ immunisation schedule included a ' 6 week, 3 month, 5 month' primary series of diphtheria, tetanus, pertussis (DTaP); polio; Haemophilus influenzae type b (Hib); and hepatitis B vaccines and; at age 15 months, measles, mumps, rubella vaccine plus a booster dose of DTaP and Hib vaccines. $^{2}$

'Practice structure and organisation' was defined as those aspects of the practice that were independent of the characteristics of a specific GP or practice nurse, but were liable to influence the care they delivered when working within that practice. These characteristics were divided into those relevant to all aspects of primary healthcare delivery by the practice and those that were specific to immunisation delivery. For example, characteristics relevant to all aspects of primary care delivery include the age at which children being seen at the practice were registered with the practice and whether or not the practice had staff shortages (that is, unfilled positions for doctors, nurses, or other practice staff). In NZ, when this study was conducted, patients could be seen as casual patients at any practice. Registration with the practice indicated that the practice was the provider of this child's preventive health care and that the practice would maintain a record of the health care received by the child. Examples of characteristics specific to immunisation delivery include whether the practice had specific immunisation clinics and whether GPs at the practice sometimes gave immunisations. 


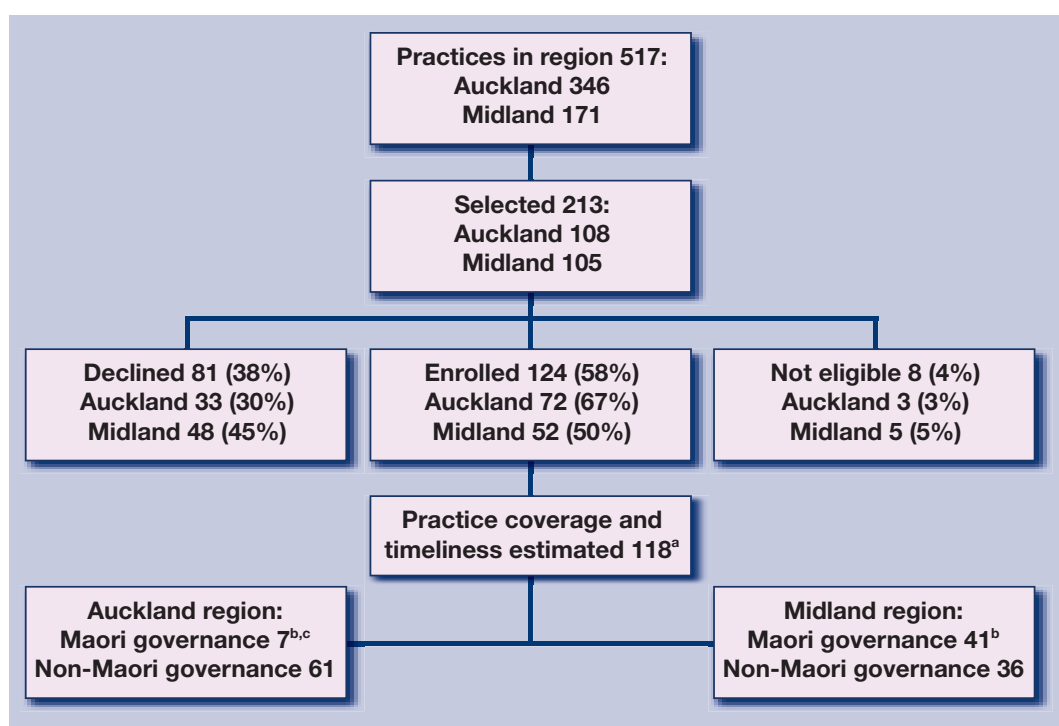

${ }^{a}$ At one practice none of the immunised children was registered. ${ }^{b}$ Coverage and timeliness for four Auckland and three Midland Maori governance practices were estimated as one practice. 'One Auckland Maori governance practice was not eligible.
Figure 1. Summary of practice recruitment and enrolment.

Figure 2. Immunisation coverage and timeliness by practice. immunised if they had received all of the 6 weeks, 3 months, and 5 months.

Immunisation coverage was defined using the third dose assumption. If the third in a series of vaccine doses was recorded as given, then it was assumed that the previous doses had also been given. ${ }^{20}$ This assumption results in a small overestimate of coverage that is less than the underestimate that occurs if only recorded doses are counted. ${ }^{20}$

The Ministry of Health's National Immunisation Register definition of timeliness was used. ${ }^{21}$ An immunisation was defined as delayed if not received within 4 weeks of the first due date for the 6 week immunisations, and within 6 weeks for 3 month, 5 month, and 15 month immunisations. ${ }^{21}$

\section{Data analysis}

Immunisation coverage and timeliness were described for the children aged 6 weeks to 23 months registered at each practice. The proportion of children fully immunised and the proportion with no delayed immunisation were transformed to facilitate analysis using the arcsin of the square root of the variable. This transformation made the variance constant across the distribution of coverage and number of children at each practice. Examination was carried out for interaction with either region or practice governance for any of the variables associated with coverage. Variables for which such interaction was present were not included in the statistical models.

A general linear model was created with arcsin of the square root of the proportion immunised as the outcome variable. For the regression analyses a base model was created that included region, practice governance, socioeconomic deprivation, and the age, and age at registration, of the children as explanatory variables. immunisations scheduled to be given at age 6 weeks, and a child aged 6 months was fully
Immunisation coverage was measured based on the child's age in relation to the immunisation schedule. For example, a child aged 10 weeks was fully immunised if they had received all of the fully immunisations scheduled to be given at age

The practice structure and organisation was practice manager, lead GP, or senior practice nurse. Practice population demographics (ethnicity and socioeconomic deprivation) were obtained from the Ministry of Health. Socioeconomic deprivation was measured using the NZDep2001 Index of reflect aspects of household material and social deprivation, and is used to group NZ households into socioeconomic quintiles or deciles. ${ }^{19}$

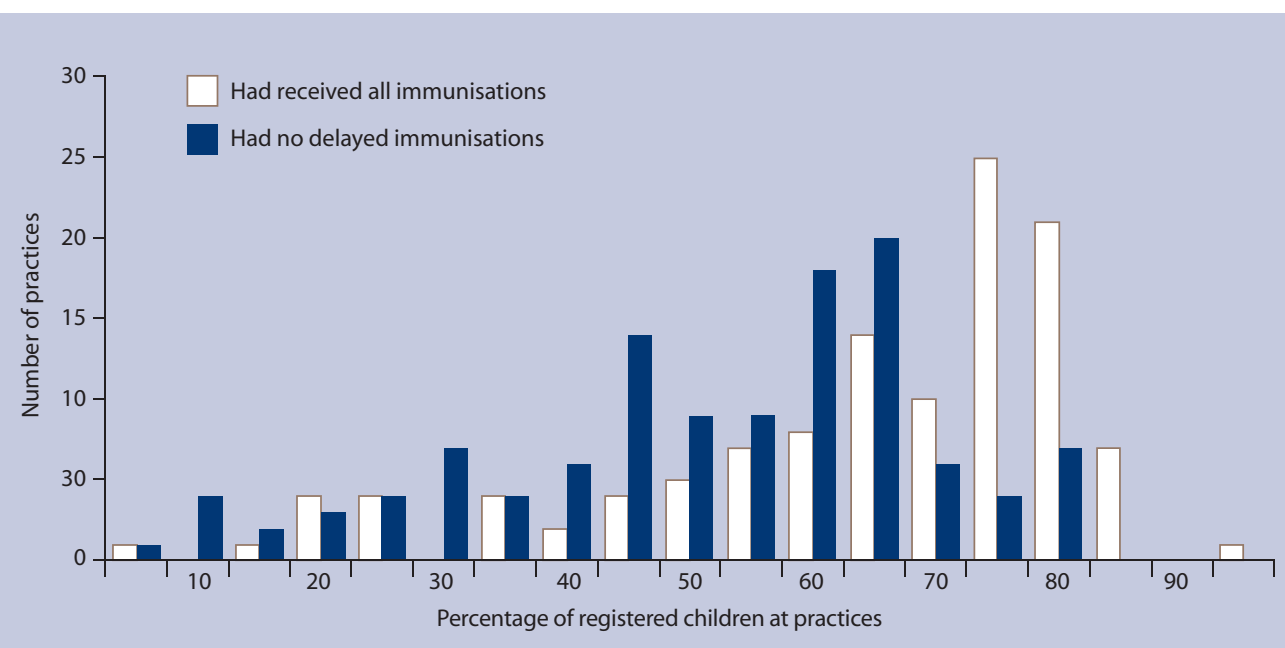
combines nine variables from the 2001 Census that 
Additional explanatory variables that described practice structure and organisation were then added to this model. Practice structure and organisational variables were retained in the final models of coverage and timeliness if they increased the model's explanatory power or remained significantly associated with practice coverage or timeliness. Analyses were performed using SAS (version 9.1; SAS Institute, Cary, NC, US).

\section{RESULTS}

\section{Practice recruitment}

There were 517 practices in the study region. A total of 213 practices $(41 \%)$ were randomly selected: 108 (31\%) in Auckland and 105 (61\%) in Midland. A small number of practices were ineligible, mainly because they did not provide Well-Child care. Thirty-nine per cent of selected practices declined to participate. The percentage of practices that declined was higher in Midland than Auckland (45\% versus $30 \%, P=$ 0.015). Practices that declined to participate were smaller (mean number of registered patients 3644 versus 4339) and had a larger proportion of registered patients living in the most deprived quintile of households (26\% versus $24 \%, P<0.001$; see Figure 1).

\section{Practice immunisation coverage and timeliness}

The median (25th to 75 th centile) number of children aged 6 weeks to 23 months registered at each practice was 116 (62-193); with these registered children being $75 \%(64-88)$ of all children in this age group seen at each practice. A median (25th to 75 th) percentage of $71 \%(57-77 \%)$ of the children registered at each practice were fully immunised and $56 \%(42-64 \%)$ were not delayed for any immunisations. The percentage of children registered at each practice that had received all immunisations and were not delayed varied widely (Figure 2). Practice immunisation coverage and timeliness were highly correlated (Spearman's rank correlation coefficient $r=0.77, P<0.001$ ).

\section{Regional, governance, socioeconomic, and age-related factors}

Practice immunisation coverage $(P<0.001)$ and timeliness $(P=0.002)$ both decreased as the socioeconomic deprivation of the registered practice population increased (Table 1). Practice coverage was higher in Midland than Auckland (73\% versus $68 \%, P=0.004)$. Immunisation timeliness was lower at Maori governance practices versus non-Maori governance practices $(P=0.03)$. Younger age at registration was associated with higher immunisation coverage $(P=0.02)$ and more timely immunisation delivery $(P=0.02)$. Coverage decreased with increasing age of the child $(P<0.001)$.

\section{Generic practice organisational features}

Four different electronic practice management

Table 1. Associations of region, practice governance, socioeconomic deprivation, child's age, and child's registration age with practice immunisation coverage and timeliness.

\begin{tabular}{|c|c|c|c|c|c|c|}
\hline \multirow[b]{2}{*}{$\begin{array}{l}\text { Practice characteristic } \\
\text { (number of practices) }\end{array}$} & \multicolumn{3}{|c|}{ Immunisation coverage } & \multicolumn{3}{|c|}{ Immunisation timeliness } \\
\hline & $\begin{array}{c}\text { Median \% } \\
\text { (25th to } 75 \text { th centile) }\end{array}$ & $\begin{array}{c}\text { Univariate } \\
P \text {-value }\end{array}$ & $\begin{array}{l}\text { Multivariate } \\
P \text {-value }\end{array}$ & $\begin{array}{c}\text { Median \% } \\
\text { (25th to } 75 \text { th centile) }\end{array}$ & $\begin{array}{l}\text { Univariate } \\
P \text {-value }\end{array}$ & $\begin{array}{c}\text { Multivariate } \\
P \text {-value }\end{array}$ \\
\hline \multicolumn{7}{|l|}{ Region } \\
\hline Auckland (68) & $68(53-75)$ & 0.020 & 0.004 & $55(41-66)$ & 0.250 & 0.350 \\
\hline Midland (50) & $73(58-79)$ & & & & & \\
\hline \multicolumn{7}{|l|}{ Practice governance } \\
\hline Maori (21) & 56 (44-62) & 0.006 & 0.110 & $40(25-47)$ & 0.002 & 0.030 \\
\hline \multirow[t]{2}{*}{ Non-Maori (97) } & $73(63-79)$ & & & $59(47-66)$ & & \\
\hline & \multicolumn{3}{|c|}{$P$-value adjusted for region and governance } & \multicolumn{3}{|c|}{$P$-value adjusted for region and governance } \\
\hline \multicolumn{7}{|c|}{$\%$ of registered patients in most deprived quintile ${ }^{b}$} \\
\hline$<30 \%(86)$ & $74(63-79)$ & $<0.001$ & $<0.001$ & $60(47-66)$ & $<0.001$ & 0.002 \\
\hline$\geq 30 \%(32)$ & $58(35-65)$ & & & $42(25-58)$ & & \\
\hline \multicolumn{7}{|c|}{ Median age of registered children at each practice } \\
\hline$<13$ months $(48)$ & $73(65-78)$ & 0.001 & $<0.001$ & $61(54-66)$ & 0.001 & 0.560 \\
\hline$\geq 13$ months $(70)$ & $64(49-77)$ & & & $48(34-63)$ & & \\
\hline \multicolumn{7}{|c|}{ Median age of children at registration } \\
\hline$<3$ months (72) & $74(63-79)$ & 0.040 & 0.020 & $60(46-66)$ & 0.140 & 0.020 \\
\hline$\geq 3$ months (46) & $63(46-73)$ & & & $47(35-62)$ & & \\
\hline
\end{tabular}

${ }^{\mathrm{a}}$ Adjusted for other variables in table with socioeconomic deprivation, age, and age at enrolment all entered into model as continuous variables. ${ }^{\mathrm{b}} \mathrm{Percentage}$ in most socioeconomically deprived quintile included in model as a continuous variable. Socioeconomic deprivation measured using the NZDep2001 Index of Deprivation, a small area-based measure that combines nine variables from the 2001 Census that reflect aspects of material and social deprivation. ${ }^{19}$ 


\begin{tabular}{|c|c|c|c|c|c|c|}
\hline \multirow[b]{2}{*}{$\begin{array}{l}\text { Practice characteristic } \\
\text { (number of practices) }\end{array}$} & \multicolumn{3}{|c|}{ Coverage } & \multicolumn{3}{|c|}{ Timeliness } \\
\hline & $\begin{array}{l}\text { Median \% } \\
\text { received all } \\
\text { immunisations } \\
\text { (25-75th centile) }\end{array}$ & $\begin{array}{l}P \text {-value } \\
\text { adjusted for } \\
\text { region and } \\
\text { governance }\end{array}$ & $\begin{array}{l}P \text {-value adjusted for } \\
\text { region, governance, social } \\
\text { deprivation } \text {, age and } \\
\text { age at registration }\end{array}$ & $\begin{array}{c}\text { Median \% } \\
\text { with no delayed } \\
\text { immunisations } \\
\text { (25-75th centile) }\end{array}$ & $\begin{array}{l}P \text {-value } \\
\text { adjusted for } r \\
\text { region and } \\
\text { governance }\end{array}$ & $\begin{array}{l}P \text {-value adjusted for } \\
\text { region, governance, social } \\
\text { deprivation }{ }^{\mathrm{a}} \text {, age, and } \\
\text { age at registration }\end{array}$ \\
\hline \multicolumn{7}{|l|}{ Generic practice factors } \\
\hline \multicolumn{7}{|c|}{ Practice management system used } \\
\hline Medtech32 (89) & $72(62-78)$ & $<0.001$ & 0.001 & $59(46-64)$ & $<0.001$ & 0.010 \\
\hline Other (28) & $63(44-76)$ & & & $42(25-60)$ & & \\
\hline \multicolumn{7}{|l|}{ Staff shortages } \\
\hline Yes (76) & $67(53-75)$ & 0.010 & 0.100 & $50(37-63)$ & 0.007 & 0.040 \\
\hline No (41) & $76(65-79)$ & & & $61(44-66)$ & & \\
\hline \multicolumn{7}{|c|}{ Practice charges for visits by registered patients } \\
\hline Yes (31) & $75(70-82)$ & $<0.001$ & 0.200 & $49(35-64)$ & 0.002 & 0.240 \\
\hline No (86) & $65(52-75)$ & & & $61(57-64)$ & & \\
\hline \multicolumn{7}{|c|}{ Percentage of patients owing money to practice } \\
\hline$>15 \%(43)$ & $62(47-73)$ & $<0.001$ & 0.270 & $47(32-62)$ & $<0.001$ & 0.180 \\
\hline$\leq 15 \%(73)$ & $75(65-80)$ & & & $60(47-66)$ & & \\
\hline \multicolumn{7}{|c|}{ Immunisation-specific practice factors } \\
\hline \multicolumn{7}{|c|}{ Specified appointments or clinics for immunisation } \\
\hline Yes (40) & $69(59-77)$ & 0.030 & 0.270 & $57(43-64)$ & 0.050 & 0.430 \\
\hline No $(77)$ & $71(57-77)$ & & & $55(38-64)$ & & \\
\hline \multicolumn{7}{|c|}{ GPs sometimes give the immunisations } \\
\hline Yes (44) & $70(64-79)$ & 0.110 & 0.580 & $60(46-66)$ & 0.020 & 0.200 \\
\hline No (73) & $70(54-75)$ & & & $55(32-62)$ & & \\
\hline \multicolumn{7}{|c|}{ Frequency of immunisation audit } \\
\hline At least monthly (32) & $72(62-77)$ & 0.005 & 0.250 & $58(47-62)$ & 0.070 & 0.900 \\
\hline Less often (85) & $70(56-77)$ & & & $51(37-65)$ & & \\
\hline
\end{tabular}

a Percentage in most socioeconomically deprived quintile included in model as a continuous variable. Socioeconomic deprivation measured using the NZDep2001 Index of Deprivation, a small area-based measure that combines nine variables from the 2001 Census that reflect aspects of material and social deprivation. ${ }^{19}$

systems were used, with one system (Medtech32, 2008, Medtech Global Ltd, Auckland, NZ) being predominant $(n=89 ; 76 \%)$. After adjustment for region, governance, social deprivation, and age, immunisation coverage $(P=0.001)$ and timeliness $(P=0.01)$ were higher at practices that used Medtech32 (Table 2).

Approximately two-thirds of practices ( $n=76$, $65 \%$ ) experienced staff shortages, with such staffing issues being associated with less timely immunisation delivery $(P=0.04)$.

While all childhood immunisation visits were free, practice charges for other visits ranged from $\$ 0$ to $\$ 30$ for children <6-years old, and from $\$ 0$ to $>\$ 60$ for adults. The majority of practices were owed money by their registered patients. At 41 practices (35\%) less than $5 \%$ of patients owed money, at 32 (28\%) 5-15\% owed money, and at $43(37 \%)$ more than $15 \%$ of patients owed the practice money.

In univariate analyses both coverage and timeliness were higher at practices that charged for visits and at practices where $15 \%$ or less of patients owed money. These associations were no longer evident after adjustment for socioeconomic deprivation.

\section{Immunisation-specific practice organisational features}

Practices varied with respect to their immunisationspecific characteristics. One-third of practices $(n=$ $40,34 \%$ ) had specific clinics or allocated appointments for immunisation. At 44 practices (38\%), GPs sometimes gave immunisations. Immunisation audits were completed at least monthly at $32(27 \%)$ practices. After adjustment for region, governance, socioeconomic deprivation, child's age, and age at registration, none of these immunisationspecific practice features were associated with coverage or timeliness. (Table 2).

\section{Multivariate analysis of generic and} immunisation-specific practice characteristics Multivariate models describing the specific practice characteristics and their associations with practice immunisation coverage and timeliness were created by the addition of these variables to the base model described (region, practice governance, social deprivation, child's age, and age at registration). In this multivariate analysis, immunisation coverage varied by region $(P=0.002)$ and was lower in practices whose registered population was more 


\begin{tabular}{|c|c|c|c|c|}
\hline & \multicolumn{2}{|c|}{ Practice immunisation coverage ${ }^{a}$} & \multicolumn{2}{|c|}{ Practice immunisation timeliness ${ }^{b}$} \\
\hline & Coefficient (95\% Cls) & $P$-value & Coefficient (95\% Cls) & $P$-value \\
\hline \multicolumn{5}{|l|}{ Region } \\
\hline Auckland & $-0.091(-0.147$ to -0.036$)$ & 0.002 & $-0.029(-0.083$ to 0.026$)$ & 0.31 \\
\hline Midland & - & & - & \\
\hline \multicolumn{5}{|l|}{ Practice governance } \\
\hline Maori & $-0.073(-0.155$ to 0.001$)$ & 0.09 & $-0.096(-0.177$ to -0.015$)$ & 0.02 \\
\hline Non-Maori & - & & - & \\
\hline $\begin{array}{l}\% \text { of registered patients in most } \\
\text { socioeconomically deprived quintile }\end{array}$ & $-0.003(-0.004$ to -0.001$)$ & $<0.001$ & $-0.003(-0.003$ to -0.003$)$ & $<0.001$ \\
\hline Median age of children at practice & $-0.001(-0.001$ to 0.000$)$ & 0.13 & 0.001 (0.000 to 0.001$)$ & 0.046 \\
\hline $\begin{array}{l}\text { Median age of children at time of } \\
\text { registration with practice }\end{array}$ & $-0.001(-0.002$ to -0.001$)$ & 0.002 & $-0.001(-0.001$ to -0.001$)$ & 0.007 \\
\hline \multicolumn{5}{|l|}{ Practice management system used } \\
\hline Medtech32 & 0.215 (0.105 to 0.324$)$ & $<0.001$ & 0.154 (0.047 to 0.26$)$ & 0.006 \\
\hline Other & - & & - & \\
\hline \multicolumn{5}{|l|}{ Practice experiences staff shortages } \\
\hline Yes & $-0.074(-0.138$ to -0.010$)$ & 0.027 & $-0.076(-0.139$ to -0.013$)$ & 0.02 \\
\hline No & - & & - & \\
\hline
\end{tabular}

${ }^{a}$ Data from 95 practices in multivariate model, $r^{2}$ for model $=0.60 .{ }^{b}$ Data from 95 practices in multivariate model, $r^{2}$ for model $=0.45$. ${ }^{c}$ Socioeconomic deprivation measured using the NZDep2001 Index of Deprivation, a small area-based measure that combines nine variables from the 2001 Census that reflect aspects of material and social deprivation. ${ }^{19}$

socioeconomically deprived $(P<0.001)$. Coverage was higher at practices where children were registered at a younger age $(P=0.002)$, used Medtech32 as their practice management system $(P<0.001)$, or did not experience staff shortages $(P=$ $0.027)$. Timeliness was lower at Maori governance practices $(P=0.020)$ and at practices whose registered population was more socioeconomically deprived $(P<0.001)$. Timeliness was higher for practices with populations with younger children $(P=$ $0.046)$, at practices where children were registered at a younger age $(P=0.007)$, at practices that used Medtech32 as their practice management system $(P$ $=0.006)$, and at practices that did not experience staff shortages $(P=0.021$; Table 3$)$.

\section{DISCUSSION}

\section{Summary of main findings}

Both immunisation coverage and timeliness varied widely in this sample of NZ general practices. Median percentages of children registered at each practice that were fully immunised $(71 \%)$ and not delayed for any immunisations (56\%) were both too low to realise the full health benefit from a national immunisation schedule.

In multivariate analyses, the practice structure and organisational factors associated with immunisation coverage and timeliness were similar. Socioeconomic deprivation of the enrolled practice population was a dominant factor in both multivariate models. For both coverage and timeliness, three practice characteristics were significant: younger age at registration, use of one of four available practice management systems, and not having staff shortages. None of the immunisation-specific practice factors explained any additional variance between practices in immunisation coverage or timeliness.

\section{Strengths and limitations of the study}

The immunisation audit was completed at each practice using computer programmes developed specifically for this purpose. Thus, an independent measure of practice immunisation delivery was obtained. For each practice this was a single point estimate and, therefore, less precise than one based on repeated measures, especially for smaller practices. ${ }^{22}$ Because of this, the regression analysis used a transformed dependent variable, with this transformation making the variance constant across the range of practices sizes.

The response rate among eligible practices was $61 \%$ and the final multivariate models of immunisation coverage and timeliness included only $95(45 \%)$ of 213 invited practices. This project coincided with a national meningococcal immunisation strategy and a large practice accreditation process in Midland; both affected practices' ability to engage with this project. Practices struggling to cope with these competing issues may have been less likely to participate in this study. Such non-participation could in part explain 
the higher practice coverage in the Midland region.

Although oversampling of Maori governance practices added complexity to the data analysis, it did ensure the study included practices serving populations for whom immunisation coverage is lower. ${ }^{2}$ If Maori governance practices had not been actively recruited, the enrolment bias towards practices that served a less socioeconomically deprived population would have been greater. Thus the authors believe the study sampling strategy helped to include a broad spectrum of practices and hence increased the generalisability of the study findings to the study region.

\section{Comparison with existing literature}

Practice registration at a younger age increases the likelihood that the first doses of the primary immunisation series are delivered on time. Timely delivery of this first immunisation is one of the strongest predictors of subsequent completion of the immunisation series. ${ }^{7}$ National immunisation registers can aid the early enrolment of a child with the practice. ${ }^{23} \mathrm{NZ}$ introduced a national immunisation register in 2005 . The present study indicates that one priority for this register must be to facilitate early enrolment of newborn infants with their primary care provider. Early enrolment is likely to lead to a stronger relationship between the practice and family. This is of particular importance in NZ where perinatal primary care is fragmented. Primary health care during pregnancy and post-partum is delivered predominantly by midwives, and the timing of transition of infant care responsibility from midwife to GP varies.

To improve immunisation delivery practice, management systems need to have a functionality that extends beyond enabling the practice to claim reimbursement for immunisations given. The quality of data in the national immunisation register is dependent on the quality of data transferred from the practice management system. Practice management systems that are used to report immunisation data are not designed specifically for this purpose. Considerable variability was observed between the different practice management systems, in terms of staff competence and confidence with the system and the ease of access that practice staff had when technical support was required. ${ }^{24}$

As was found in this project, and as has been shown in other primary care practices in NZ, the quality of immunisation data that such systems report is variable. ${ }^{24,25}$ Practice management systems used in NZ have design features that can minimise data entry errors. However, currently, the systems enable users to alter these features, thus introducing practice-level variability in recording of immunisation data.
Preventive health service delivery is particularly vulnerable to staff shortages and high staff turnover. Understaffed practices do not have the time or the consistency of personnel to reflect upon their work and adopt a proactive rather than a reactive approach to service delivery issues. General practices in NZ do have a preventive service orientation, but there is variability in how well individual practices use their practice management systems to support immunisation delivery. Important aspects include office coordination of preventive services, a system to ensure all visits become preventive care opportunities, and regular performance monitoring. ${ }^{26}$

Staffing shortages may also reflect broader issues of organisational culture and practice leadership. They reflect how people work together, communicate, and resolve conflict within a general practice. ${ }^{26}$ Staff shortages are financially costly for a practice, with the resources spent on recruitment and training not available for service delivery. ${ }^{27}$

The socioeconomic deprivation of the practice population was a consistently strong determinant of practice immunisation delivery in both the coverage and timeliness models. Poverty and factors related to poverty are recognised as being among the more persistent barriers to immunisation. ${ }^{13,28}$ The significance of this for children living in poorer households is increased by such households also being places where exposure to vaccine-preventable disease is increased. ${ }^{29}$

The relationship between socioeconomic deprivation and practice immunisation delivery appears to be specific rather than a more general feature across all indicators of quality of primary care. ${ }^{30}$ This is probably a reflection of immunisationspecific issues. Examples of such issues include the necessity for multiple appointments to receive the complete immunisation series, and the contribution of missed immunisation opportunities that occur at acute illness visits. ${ }^{31,32}$ Children living in more socially deprived households have more frequent episodes of acute illness. Healthcare visits for such illnesses account for the majority of missed immunisation opportunities. ${ }^{32}$

\section{Implications for clinical practice}

Wide variability between primary care practices in preventive service delivery to children is acknowledged as a current weakness of primary care in the US. ${ }^{33}$ This study indicates that such variability is also a current weakness of primary care in NZ. Important practice characteristics include staffing levels and stability, practice orientation to preventive services, and adaptation to the population context in which preventive service delivery occurs. ${ }^{26}$ 
This study implies that these basic issues of primary care structure and organisation need to be addressed to obtain full return on immunisationspecific initiatives.

\section{Funding body}

This project was funded predominantly by the Health Research Council and the Ministry of Health Immunisation Research Strategy through the Health Research Council of New Zealand Partnership Programme. The project was also supported by two smaller grants (each for less than $10 \%$ of the project budget) received from GlaxoSmithKline and the Royal New Zealand College of General Practitioners. The Immunisation Research Strategy funded the employment of staff necessary to recruit participants, collect, manage, analyse, and report the data. The GlaxoSmithKline grant was used to pay staff involved in data collection. The Royal New Zealand College of General Practitioners grant was used to recompense enrolled practices for their time.

\section{Ethical approval}

Approval was obtained from the Ministry of Health Northern X Ethics Committee. AKX/04/09/265 'General practice and health professional determinants of immunisation coverage'.

\section{Competing interests}

Cameron C Grant completed a consultancy on rotavirus gastroenteritis for GlaxoSmithKline during 2005 and 2006. Nikki M Turner, Deon G York, Felicity Goodyear-Smith, and Helen A Petousis-Harris have no competing interests to declare. None of the authors has any financial interest in any of the practice management systems used by the practices enrolled in this study.

\section{Discuss this article}

Contribute and read comments about this article on the Discussion Forum: http://www.rcgp.org.uk/bjgp-discuss

\section{REFERENCES}

1. Plotkin SA, Orenstein WA. Vaccines. 4th edn. Philadelphia: Elsevier Inc, 2004.

2. Ministry of Health. Immunisation handbook 2006. Wellington: Ministry of Health, 2006.

3. Somerville RL, Grant CC, Grimwood K, et al. Infants hospitalised with pertussis: estimating the true disease burden. J Paediatr Child Health 2007; 43(9): 617-622.

4. Elliott E, McIntyre P, Ridley G, et al. National study of infants hospitalised with pertussis in the acellular vaccine era. Pediat Infect Dis J 2004; 23(3): 246-252.

5. Van Buynder PG, Owen D, Vurdien JE, et al. Bordetella pertussis surveillance in England and Wales: 1995-7. Epidemiol Infect 1999; 123(3): 403-411.

6. Tanaka M, Vitek CR, Pascual FB, et al. Trends in pertussis among infants in the United States, 1980-1999. JAMA 2003; 290(22): 2968-2975.

7. Guyer B, Hughart N, Holt E, et al. Immunization coverage and its relationship to preventive health care visits among inner-city children in Baltimore. Pediatrics 1994; 94(1): 53-58.

8. Grant CC, Roberts M, Scragg R, et al. Delayed immunisation and risk of pertussis in infants: unmatched case-control study. BMJ 2003; 326(7394): 852-853.

9. Bobo JK, Gale JL, Thapa PB, Wassilak SG. Risk factors for delayed immunization in a random sample of 1163 children from Oregon and Washington. Pediatrics 1993; 91(2): 308-314.

10. Anonymous. Immunisation policy: recipes for success. Lancet 1987; 2(8550): 78-80

11. Nicoll A, Elliman D, Begg NT. Immunisation: causes of failure and strategies and tactics for success. BMJ 1989; 299(6703): 808-812.

12. Lister S, McIntyre PB, Burgess MA, O’Brien ED. Immunisation coverage in Australian children: a systematic review 1990-1998. Commun Dis Intell 1999; 23(6): 145-170.

13. Anonymous. Strategies to sustain success in childhood immunizations. The National Vaccine Advisory Committee. JAMA 1999; 282(4): 363-370.

14. Gindler JS, Cutts FT, Barnett Antinori ME, et al. Successes and failures in vaccine delivery: evaluation of the immunization delivery system in Puerto Rico. Pediatrics 1993; 91(2): 315-320.

15. Williams IT, Milton JD, Farrell JB, Graham NM. Interaction of socioeconomic status and provider practices as predictors of immunization coverage in Virginia children. Pediatrics 1995; 96(3 Pt 1): 439-446.

16. Kimmel SR, Burns IT, Zimmerman RK. Addressing immunization barriers, benefits, and risks. J Fam Pract 2003; 52(1 Suppl): S47-55.

17. Sabnis SS, Pomeranz AJ, Lye PS, Amateau MM. Do missed opportunities stay missed? A 6-month follow-up of missed vaccine opportunities in inner city Milwaukee children. Pediatrics 1998; 101(5): E5.

18. Ministry of Health. Maori providers: primary health care delivered by doctors and nurses: The National Primary Medical Care Survey (NatMedCa): 2001/02 Report 3. Wellington: Ministry of Health, 2004.

19. Crampton P, Salmond C, Kirkpatrick R. Degrees of deprivation in New Zealand: an atlas of socioeconomic difference (2001 edition). Auckland: David Bateman Ltd, 2004

20. Hull BP, Lawrence GL, MacIntyre CR, McIntyre PB. Estimating immunisation coverage: is the 'third dose assumption' still valid? Commun Dis Intell 2003; 27(3): 357-361.

21. Ministry of Health. National immunisation register. http://www.moh.govt.nz/nir (accessed 27 Aug 2009).

22. Barker LE, Smith PJ, Gerzoff RB, et al. Ranking states' immunization coverage: an example from the National Immunization Survey. Stat Med 2005; 24(4): 605-613.

23. Freeman VA, DeFriese GH. The challenge and potential of childhood immunization registries. Annu Rev Public Health 2003 24: $227-246$.

24. Goodyear-Smith F, Grant C, York D, et al. Determining immunisation coverage rates in primary health care practices: a simple goal but a complex task. Int J Med Inform 2008; 77(7): $477-485$.

25. Poskitt N, Taft S. National Immunisation Register inaccuracies and duplications. NZ Med J 2009; 122(1288): 113.

26. Randolph G, Fried B, Loeding L, et al. Organizationa characteristics and preventive service delivery in private practices: a peek inside the 'black box' of private practices caring for children. Pediatrics 2005; 115(60): 1704-1711.

27. Waldman JD, Kelly F, Arora S, Smith HL. The shocking cost of turnover in health care. Health Care Manage Rev 2004; 29(1): 2-7.

28. Lynch M. Effect of practice and patient population characteristics on the uptake of childhood immunizations. Br J Gen Pract 1995; 45(393): 205-208.

29. Singleton R, Holve S, Groom A, et al. Impact of immunizations on the disease burden of American Indian and Alaska native children. Arch Pediatr Adolesc Med 2009; 163(5): 446-453.

30. Ashworth M, Seed P, Armstrong D, et al. The relationship between social deprivation and the quality of primary care: a national survey using indicators from the UK Quality and Outcomes Framework. Br J Gen Pract 2007; 57(539): 441-448.

31. Cohen NJ, Lauderdale DS, Shete PB, et al. Physician knowledge of catch-up regimens and contraindications for childhood immunizations. Pediatrics 2003; 111(5 Pt 1): 925-932.

32. Turner N, Grant C, Goodyear-Smith F, Petousis-Harris H. Seize the moments: missed opportunities to immunize at the family practice level. Fam Pract 2009; 26(4): 275-278

33. Institute of Medicine. Crossing the quality chasm: a new health system for the 21st century. Washington, DC: Institute of Medicine, 2001. 